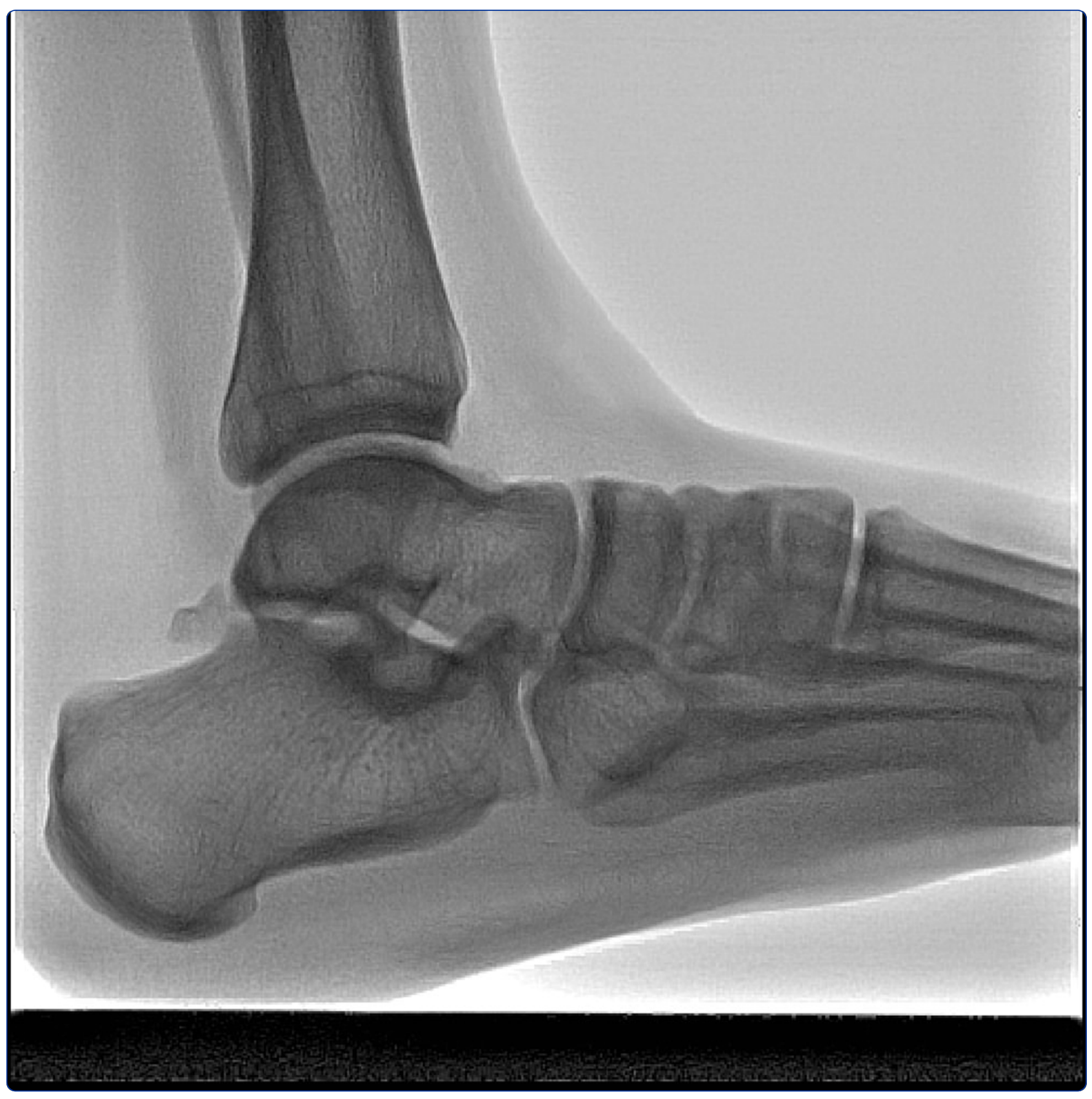

Analysis of the talocrural and subtalar joint motions in patients with medial tibial stress syndrome

Akiyama et al. 


\title{
Analysis of the talocrural and subtalar joint motions in patients with medial tibial stress syndrome
}

Kei Akiyama ${ }^{1,2^{*}}$, Byungjoo Noh $^{3}$, Mako Fukano ${ }^{4}$, Shumpei Miyakawa ${ }^{3}$, Norikazu Hirose ${ }^{4}$ and Toru Fukubayashi ${ }^{4}$

\begin{abstract}
Background: The rearfoot motion during sports activities in patients with the medial tibial stress syndrome (MTSS) is unknown. This study aimed to investigate the difference in kinematics of the rearfoot in MTSS patients (eight male soccer players) and control participants (eight male soccer players) during a forward step.

Methods: Sixteen male soccer players, including eight players with MTSS, participated. Forward step trials were recorded with cineradiographic images obtained at a sampling rate of $60 \mathrm{~Hz}$. Geometric bone models of the tibia and talus/calcaneus were created from computed tomography scans of the distal part of one lower limb. Following a combination of approaches, anatomical coordinate systems were embedded in each bone model. The talocrural joint motion (relative motion of the talus with respect to the tibia) and subtalar joint motion (relative motion of the calcaneus with respect to the talus) were examined.

Results: A significantly larger range of internal/external rotation and inversion/eversion motion was observed in the subtalar joint of MTSS patients compared to healthy controls $(P<0.05)$ from heel contact to heel off. There were no significant differences between the MTSS patients and healthy participants in the ranges of all talocrural joint angles during the forward step.

Conclusion: Our results indicate that the range of subtalar joint motion is greater in patients with MTSS during the stance phase of the forward step. The kinematic results obtained of this study may have important clinical implications and add quantitative data to an in vivo database of MTSS patients.
\end{abstract}

Keywords: Medial tibial stress syndrome, Subtalar joint, Talocrural joint, 3D to 2D registration technique

\section{Background}

The medial tibial stress syndrome (MTSS), first described by Mubarak et al. in 1982 [1], is one of the most common painful exercise-induced leg injuries [2, 3]. MTSS encompasses several injuries, including medial tibial periostitis, soleus enthesopathy, and shin splints [3, 4]. However, the aetiology of this condition has been debated for years, and MTSS continues to be an intriguing and confusing pathological condition. Pain associated with MTSS commonly occurs in the middle or distal third of the posteromedial border of the tibia $[3,5]$. The site of pain is typically

\footnotetext{
* Correspondence: k-akisan@suou.waseda.jp

'Graduate School of Sport Sciences, Waseda University, 2-579-15 Mikajima,

Tokorozawa, Saitama 359-1192, Japan

${ }^{2} J a p a n$ Institute of Sports Sciences, Sports Science, 3-15-1, Nishigaoka, Kita-ku 115-0056, Japan

Full list of author information is available at the end of the article
}

spread over a minimum of $5 \mathrm{~cm}$ [6]. In contrast, a stress fracture has an area of focal tenderness of only $2-3 \mathrm{~cm}$ [7, 8]. Advanced MTSS patients commonly experience pain at the onset of activity [9]. Military studies have indicated that the incidence of MTSS is $6-38 \%[5,6,10]$. The recovery time for the resolution of MTSS ranges from 4 weeks to 18 months $[9,11]$, and MTSS is often refractory to conservative management. MTSS is proposed to be triggered by internal (tibial alignment, flat foot, low medial longitudinal arch, and forefoot varus) and external factors (over work, sports surface, shoes) [5, 6, 12], although these causes remain largely speculative. A previous study suggested the use of an evidence-based prevention method [13], but effective methods for treatment and prevention have not been established and further studies of MTSS are urgently required. An assessment of the static 
and dynamic alignment of the rearfoot in MTSS is necessary to understand the kinematics related to MTSS.

Static malalignment of the lower extremity has been shown to increase the risk of developing MTSS in athletes $[12,14]$. In addition, many studies have reported the kinematic characteristics of MTSS, such as rearfoot eversion [15, 16], increased free moment [17] and loading rates [18], tibial shock [19], and hip external rotation $[14,20]$. However these studies performed motion analysis with skin markers. Skin markers mounted upon externally identifiable bony landmarks of the foot do not follow the underlying individual skeletal segments during movement [21]. Motion analysis using skin markers does not allow the investigation of the subtalar joint (especially talus) movement [22]. Intracortical pins have also been used to more accurately measure in vivo rearfoot motion kinematics [23, 24], but this method is invasive and the restricted motion of bone pin markers makes these internal markers difficult to implement. In contrast, 3-dimensional to 2-dimensional (3D-2D) model registration techniques have been used for the analysis of rearfoot motion without the use of invasive markers $[25,26]$. However, no prior study has used 3D-2D model registration to assess static and dynamic rearfoot behaviour in MTSS. The 3D-2D model allows to study the characteristics of patients with MTSS in terms of malalignment and kinematics, contributing to an improved understanding of MTSS.

Therefore, the aim of the present study was to investigate MTSS using 3D-2D model registration to obtain accurate structures of the rearfoot during the forward step. Hypothesis was set that MTSS patients would have greater subtalar joint pronation (dorsi flexion, eversion, external rotation), compared to healthy individuals, during the forward step.

\section{Methods \\ Participants}

The Ethics Committee of our institution approved the study protocol. A thorough explanation was provided to participants and consent was obtained from all participants. All participants belonged to the same university soccer team. The study population included eight male soccer players [age, $21.1 \pm 2.1 \mathrm{y}$; body height, $174.6 \pm 6.7 \mathrm{~cm}$; body mass, $73.0 \pm 5.7 \mathrm{~kg}$; mean \pm standard deviation (SD)] with MTSS and eight healthy soccer players [age, $19.6 \pm$ 2.8 years; body height, $172.9 \pm 5.3 \mathrm{~cm}$; body mass, $71.0 \pm$ $12.1 \mathrm{~kg}$; mean \pm standard deviation (SD)]. Between May 2011 and April 2013, Patients who had been diagnosed with MTSS by an experienced orthopaedic surgeon within a period of 6 months were recruited. The right lower leg was involved in six patients and the left lower leg was involved in two patients. MTSS was defined as exerciseinduced pain in the posteromedial aspect of the tibia, and pain on palpation in an area of $\geq 5 \mathrm{~cm}$ in the posteromedial tibial region, based on the diagnostic criteria described by Yates and White [6]. All patients had experienced symptoms for at least two weeks, and MTSS patients who had undergone previous surgery were excluded. None of the healthy participants (eight right feet) had a history of surgery in their lower legs.

\section{Cineradiography (2D)}

To investigate rearfoot movement during the stance phase of the forward step, we recorded forward step trials on a platform (Fig. 1). Participants first stood straight with both feet together to record the static lower extremity position (relaxed neutral standing position with knees straight). The participants then ran with a normal stride, with the second toe of the foot and heel contacting a line parallel to the direction of movement. We confirmed that the foot was parallel to the tape (parallel to direction of the movement) on the platform during all data collection. During the participants first step, we recorded the foot (right foot of healthy participants, foot corresponding to the side of MTSS) that was grounded (i.e., when one foot contacted the platform, the other foot was off the platform). The forward step pitch was set at 2.5 steps/s using a metronome. Each forward step trial was recorded using cineradiography (Infinix Celeve-1 INFX-8000C, Toshiba Medical Inc., Tochigi-ken, Japan). Acquired orthogonal images squared the foot and the central ray. Eight inch square images were obtained at 60 frames/s, with an expected radiation exposure equivalent of $200 \mathrm{~mA}(1 \mathrm{~ms})$ with an intensity of $50 \mathrm{kV}$, expected $15 \mathrm{mGy}$.

\section{Bone model (3D)}

Geometric bone models of the tibia and talus/calcaneus were created from the study leg of all participants by computed tomography scans (IDT 16, Philips Healthcare, Best, The Netherlands) at a $0.4 \mathrm{~mm}$ slice thickness, scanning $15 \mathrm{~cm}$ above the rearfoot and below the calcaneus. The bone model ranges were defined using Image J (open source, http://imagej.nih.gov/ij/). Before segmenting the bone models, we converted dicom files to analysis files. Each subject's bone image was loaded using ITK-SNAP (open source, http://www.itksnap.org/pmwiki/pmwiki.php). Each bone was segmented with cortical bone as the border, and these points (approximately $3000-10,000$ points) were converted into polygonal surface models [3D bone models (tibia and talus/calcaneus)].

\section{Anatomical coordinate systems}

3D bone model anatomical coordinate systems were set (Geomagic Studio, 3D Systems, Rock Hill, SC, USA) following a combination of previously reported approaches (Fig. 2a, b, c) [27]. The axis of the tibia was defined as follows. The origin of the tibia was the flat center of the 


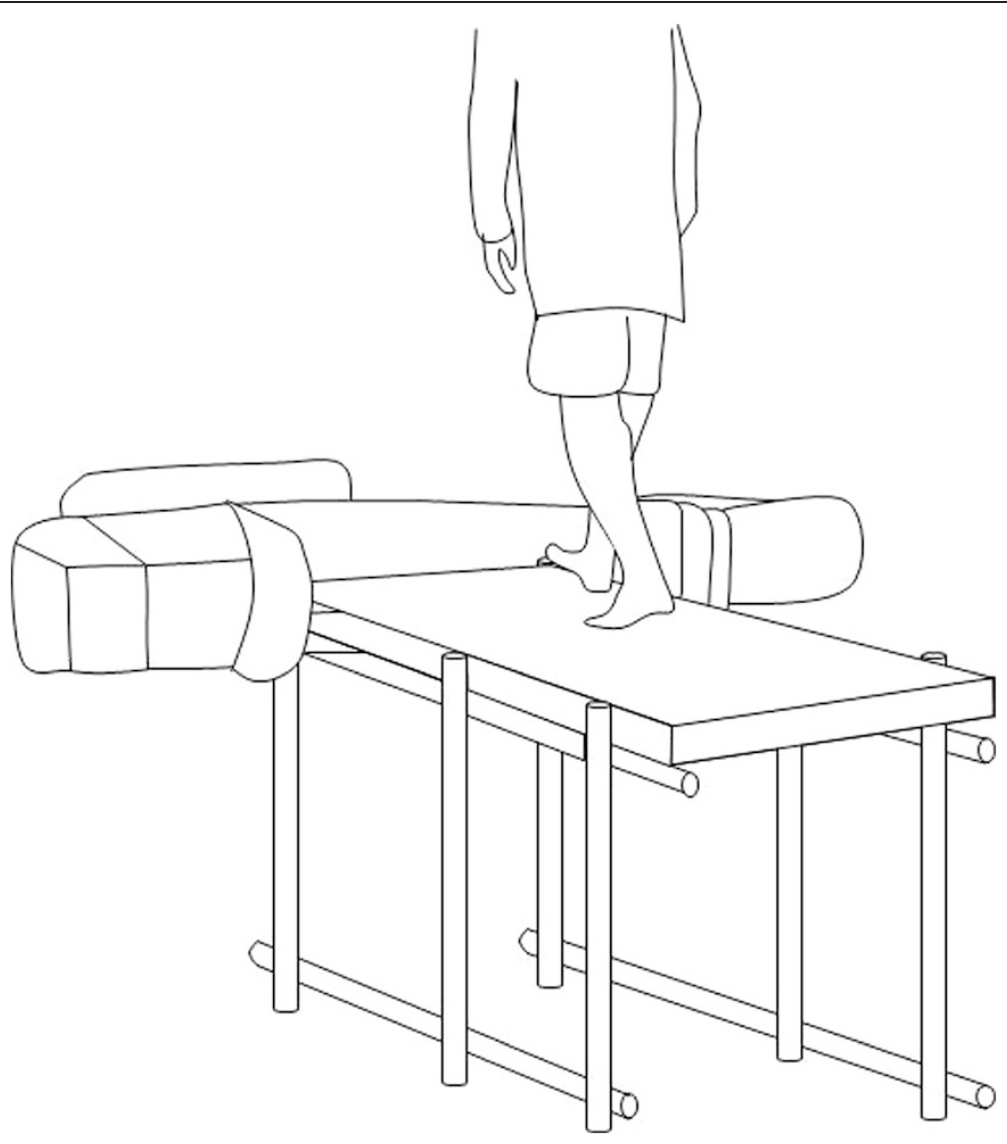

Fig. 1 Setup of the data measurements. Participants performed a forward step on a cineragiography table $(1 \mathrm{~m} \times 1.5 \mathrm{~m} \times 0.8 \mathrm{~m}$, height-width-depth)

tibial plafond. The anteroposterior axis was defined as an orthogonal line to the anterior edge line of the tibial plafond passing through the origin. The superoinferior axis was defined as a line connecting the medial-lateral and anteroposterior center points of the distal tibial shaft at 5 and $10 \mathrm{~cm}$ above the joint surface, passing through the origin. The $Z$-axis was defined as a line perpendicular to the $X$ - and $Y$-axes (Fig. 2a). The axis of the talus was defined as follows. A circle on the sagittal plane fit to two midpoints (the midpoint of the anteromedial and anterolateral edges and the midpoint of posteromedial and posterolateral edges of the trochlea tali) was defined. The origin of the talus was defined as the centre of the circle. The $Z$-axis was defined as a perpendicular line to the
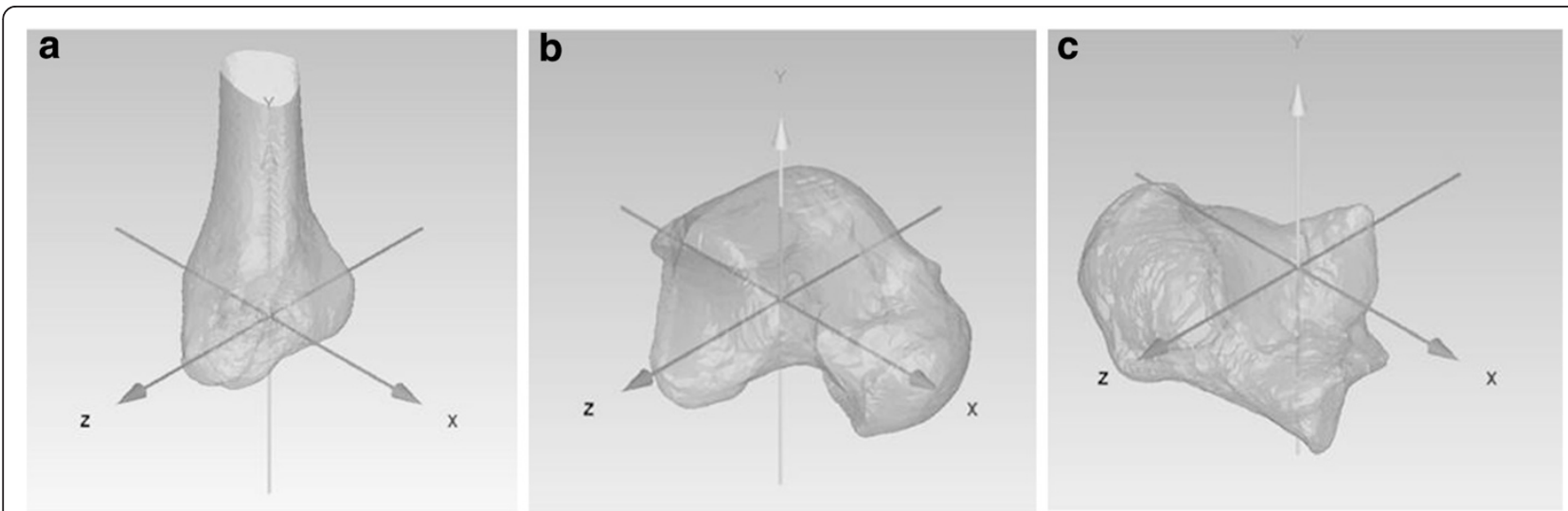

Fig. 2 An example of the geometric bone model. (a: tibia, b: talus, c: calcaneus) After geometric bone models of the tibia and talus/calcaneus were created from computed tomography scans, 3D bone model anatomical coordinate systems were set 
circle, passing through the origin. The $Y$-axis was defined as a line passing through the origin and circle at the highest point of the tibial tali. The $X$-axis was the cross product of the $Y$ and $Z$-axes (Fig. 2b). The axis of the calcaneus was defined as follows. The origin was the center of a line connecting the most lateral point of the middle talar articular surface and posterior talar articular surface. The $X$-axis was a line parallel to the inferior calcaneus, passing through the origin. The $Y$-axis was a line parallel to the lateral wall of the calcaneus and perpendicular to the $X$-axis, passing through the origin. The $Z$-axis was the cross product of the $X$ - and $Y$-axes (Fig. 2c). The angle of the rearfoot relative to the tibia, and the tibia relative to the laboratory coordinate system, were calculated according to Grood and Suntay [28].

\section{$3 \mathrm{D}$ to $2 \mathrm{D}$ registration technique}

Three-dimensional kinematics of the tibia, talus, and calcaneus models were determined using a shape matching technique [29] and custom software (Joint Track, open source, http://sourceforge.net/projects/jointtrack/). A previous study that used an identical analysis indicated that the average intraobserver differences for the rearfoot were $0.35 \mathrm{~mm}$ for an out-of-plane translation and $0.85^{\circ}$ for rotations [27]. The average interobserver differences for the rearfoot were $0.35 \mathrm{~mm}$ for an out-of-plane translation and $0.76^{\circ}$ for rotations [27]. In this study, Intraclass correlation (ICC) was measured by comparing 3 measurements by the same investigator for each of the 16 ankles. The ICC were as follows: dorsi-plantar flexion, 0.92 ; inversion-eversion, 0. 81; internal-external rotation, 0.79 .

The tibia, talus, and calcaneus models were matched with $2 \mathrm{D}$ images after modelling. In vivo rearfoot positions were then reproduced from the 3D rearfoot model (Fig. 3a). The following types of rearfoot motion were examined: motion of the talocrural joint (relative motion of the talus with respect to the tibia) and motion of the subtalar joint (relative motion of the calcaneus with respective to the talus). The rearfoot positions at different time intervals were then reproduced from a series of 3D rearfoot models from heel contact (Fig. 3b) to heel off (Fig. 3c) during a forward step. Plantarflexion/dorsiflexion was defined as the rotation along the mediolateral axis, internal/external rotation was the rotation along the superoinferior axis, and inversion/eversion was the rotation along the anteroposterior axis. All kinematics data were normalized relative to the weight-bearing stance phase where the heel strike occurred at zero percent and heel off at $100 \%$ of the stance phase.

\section{Navicular height change and calcaneal pitch (Static alignment)}

Before the forward step trials, the navicular height change was radiologically assessed. The perpendicular distance
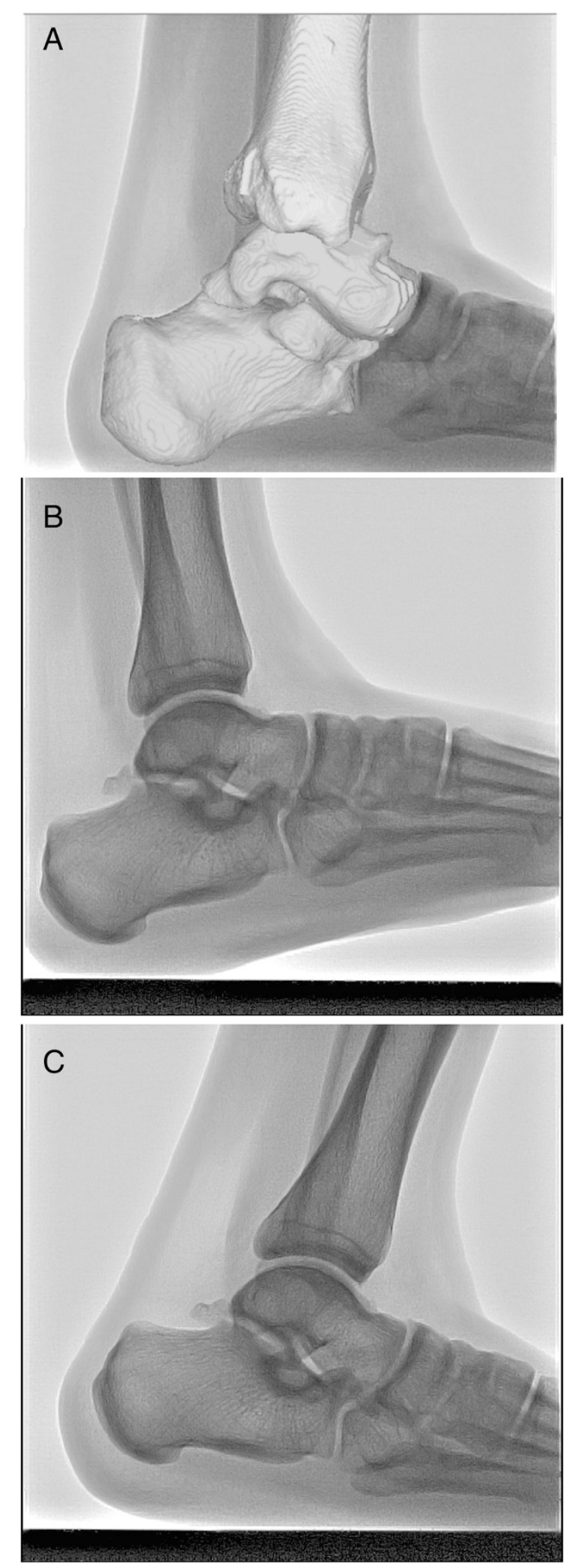

Fig. 3 Cineradiography of left foot. a: The tibia, talus, and calcaneus models were matched, $\mathbf{b}$ : heel contact, $\mathbf{c}$ : heel off 
between the navicular tuberosity (mid point of navicular in a vertical direction) and a line connecting the lower end of the calcaneus and the lower end of the first metatarsal was then measured. Participants kept the non-weight bearing leg in front of the other leg (non-weight bearing). The test was repeated with the participants standing on both feet, shoulder width apart (weight-bearing). The values of the two measurements were subtracted to obtain the navicular height change. The ICC when the same examiner measured 16 ankles 3 times was 0.89 . The calcaneal pitch was defined as the angle formed by drawing a line along the inferior border of the calcaneus and a line drawn in the horizontal from a standing lateral radiograph (weight-bearing) [30, 31].

\section{Statistical analysis}

For all kinematics of subtalar joint motion and talocrural joint motion from heel strike to heel off, a two-way analysis of variance was conducted as condition (control and MTSS) $\times$ time. Whether the movement of the subtalar joint between groups was different in various stages of foot contact was checked. With significant interactions, the main effect for each factor was examined. Multiple comparisons confirmed that there was a correlation between the main effect and the interaction. An unpaired $t$-test was used to compare the differences in range of motion (dorsi-plantar flexion, inversion-eversion, internalexternal rotation) of the control and MTSS participants. Ninety-five percent confidence intervals were calculated. Statistical significance was at $P<0.05$. Effect size of the unpaired $t$-test was calculated in $\left|\mathrm{t}_{0}\right|(\sqrt{1 / \mathrm{n} 1+1 / \mathrm{n} 2})$. The Kolmogorov-Smirnov test was carried out to check whether the probability distribution of the two populations was different; all the kinematics were normally-distributed.

\section{Results}

\section{Subtalar joint}

There was a significant difference in the external rotation and eversion motions of the subtalar joint during 20-30\% of foot contact between MTSS patients and healthy participants. In the subtalar joint of MTSS patients, a significantly larger range of internal/external rotation and inversion/eversion motion was observed $(P<0.05)$ compared to healthy controls, from heel contact to heel off (Fig. 4). In contrast, no statistical difference was observed in subtalar plantarflexion/dorsiflexion between the two groups (Table 1).

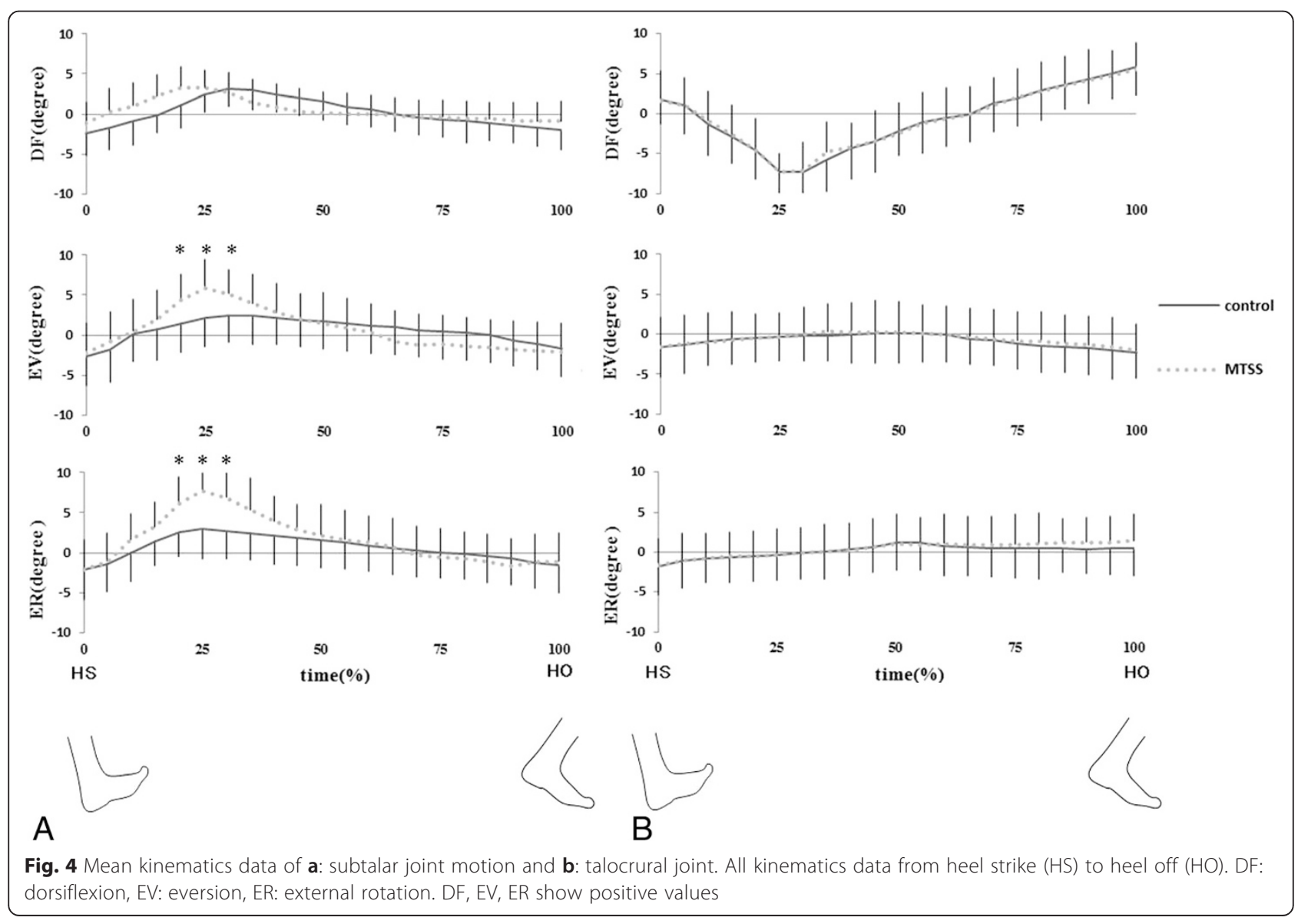


Table 1 Range of motion, calcaneal pitch, and navicular height change in patients with and without MTSS. Joint range of motion during forward step in control participants and MTSS patients. Calcaneal pitch and navicular height change were measured as static alignment in control and MTSS patients

\begin{tabular}{|c|c|c|c|c|c|}
\hline & & Control $(n=8)$ & MTSS $(n=8)$ & & \\
\hline & & $\mathrm{MEAN} \pm \mathrm{SD}$ & $\mathrm{MEAN} \pm \mathrm{SD}$ & & ES \\
\hline \multirow[t]{3}{*}{ Subtalar joint } & $\mathrm{DF}(+) / \mathrm{PF}(-)\left({ }^{\circ}\right)$ & $6.1 \pm 0.7$ & $6.1 \pm 1.2$ & & 0.1 \\
\hline & $\mathrm{EV}(+) / \mathrm{IV}(-)\left(^{\circ}\right)$ & $5.3 \pm 0.4$ & $7.8 \pm 1.3$ & * & 2.6 \\
\hline & $\mathrm{ER}(+) / \mathbb{R}(-)\left({ }^{\circ}\right)$ & $5.5 \pm 1.1$ & $9.8 \pm 0.9$ & $*$ & 4.2 \\
\hline \multirow[t]{3}{*}{ Taloclural joint } & $\mathrm{DF}(+) / \mathrm{PF}(-)\left(^{\circ}\right)$ & $13.7 \pm 2.2$ & $13.6 \pm 2.7$ & & 0.1 \\
\hline & $\mathrm{EV}(+) / \mathrm{IV}(-)\left(^{\circ}\right)$ & $2.9 \pm 1.0$ & $3.4 \pm 2.2$ & & 0.3 \\
\hline & $\operatorname{ER}(+) / \operatorname{IR}(-)\left(^{\circ}\right)$ & $3.5 \pm 1.0$ & $3.7 \pm 1.1$ & & 0.2 \\
\hline Calcaneal pitch & $\left({ }^{\circ}\right)$ & $20.8 \pm 5.2$ & $14.3 \pm 3.8$ & * & 1.5 \\
\hline Navicular height change & $(\mathrm{cm})$ & $0.7 \pm 0.2$ & $0.9 \pm 0.1$ & * & 1.4 \\
\hline Time of Stance phase & (msec) & $319 \pm 9$ & $323 \pm 9$ & & .0 \\
\hline
\end{tabular}

PF Plantarflexion, DF Dorsiflexion, IV Inversion, EV Eversion, IR Internal rotation, ER External rotation, ES Effect size ${ }^{*} p<0.05$

\section{Talocrural joint}

There was no significant difference in talocrural joint motion from heel strike to heel off between MTSS patients and healthy participants. There was also no significant difference in the range of all talocrural joint angles during the forward step between the MTSS patients and healthy participants (Table 1).

\section{Navicular height change and calcaneal pitch (Static alignment)}

The navicular height change and calcaneal pitch in the MTSS patients were significantly lower than in healthy participants (Table $1 ; P<0.05$ ).

\section{Discussion}

The purpose of this study was to reveal the characteristics of the static alignment and rearfoot motion during a forward step in MTSS patients. The subtalar joint of patients with MTSS was characterized by an increased range of motion in internal/external rotation and inversion/ eversion during the forward step. In addition, the calcaneal pitch was lower and the navicular height change was greater in MTSS patients.

\section{Pronation in MTSS patients}

In this study, MTSS patients showed more external rotation and eversion of the subtalar joint than that observed in normal participants. Moreover, the kinematics of the subtalar joint had a tendency in almost every case.

Campbell et al. reported an eversion peak of $8.7^{\circ}$ for the normative rearfoot (calcaneus relative to tibia) during walking with biplane cineradiography [32]. With regard to the difference in the magnitude of eversion in this study compared to the Campbell study, this may have occurred because the rearfoot movement in this study included the subtalar joint and the talocrural joint.
The previous study is research related to the motion of dynamic foot in MTSS patients. Pohl et al., using logistic regression analysis, indicated that in female runners with tibial stress fractures, peak rearfoot eversion during a forward step was an important variable [15]. Standing foot pronation and longitudinal arch were greater in MTSS patients than in healthy participants $[12,33]$. However, these previous studies employed uniplanar measurements. It is significant that our study used the 3D-2D model registration technique to evaluate the 3-dimensional kinematic characteristics of MTSS patients during a forward step.

Recently, several studies have investigated the relationship between MTSS and the kinematics of the lower extremity. The occurrence of tibial stress fractures in female runners was related to greater vertical loading rates of the lower extremity [17]. Athletes with shin splints had increased rear foot inversion and eversion during passive mobility [16]. Additionally, peak rearfoot eversion in athletes with MTSS [16] and peak rearfoot eversion of athletes with tibial stress fractures were significantly higher than those of normal participants [34]. Thus, the lower extremity that is affected by MTSS is believed to be associated with abnormal foot motion.

However, the pathophysiology of MTSS has been a subject of controversy.

The potential development of methods for preventing MTSS requires further study to investigate how subtalar pronation affects MTSS injury.

\section{Increased navicular height change in MTSS patients (Static alignment)}

In this study, we found that static navicular height change was greater in MTSS patients compared to healthy participants. Several studies have examined the relationship between navicular drop and MTSS [10, 24, 35, 36]. The use of navicular drop to assess foot pronation has been 
especially useful in MTSS patients [24]. Additionally, a point-biserial correlation of 0.42 between the navicular drop test and the occurrence of MTSS was discovered, indicating a positive relationship between navicular drop, a measure of pronation, and MTSS injury [10]. In these studies, the navicular drop was greater in MTSS patients than in healthy participants [10, 24]. In contrast, Hubbard et al. reported that there was no relationship between MTSS and navicular drop [37]. These conflicting results are possibly caused by methodological differences. Almost all studies evaluated navicular drop using skin markers, and the reliability of this method has been reported as difficult to evaluate [34]. The present study used radiography, which is a more precise method, and we found that navicular height change was greater in MTSS patients.

\section{Calcaneal pitch in MTSS patients (Static alignment)}

In the present study, the calcaneal pitch was lower in MTSS patients compared to healthy participants $\left(14.3^{\circ}\right.$ vs. $20.75^{\circ}, p=0.017$ ), indicating that a low calcaneal pitch may be associated with MTSS. Other researchers found that the calcaneal pitch of normal participants was $20^{\circ}-22.5^{\circ}$ during standing [31,38]. The calcaneal pitch angle is to patients with pes planus [30], and the presence of flat-feet types are used to patients with lower extremity injuries [39].

\section{Limitations}

There are several limitations to the current study. First, considering the anatomy and functions of the rearfoot, more specific and precise studies concerning the subtalar joint are needed to validate the accuracy of the analysis. Second, our analysis range included only one forward step starting from a static standing position. Sports activities have a number of movements (e.g., running, cutting, stopping and turning, etc.), and therefore, further investigation of these motions in MTSS patients is needed. Third, the measurement of activity was limited to a single event to minimize radiation exposure. Importantly, the participants practiced the activity before the recorded event to ensure reproducibility and reduce inter-subject variability. Finally, the precision of the bone model in this study was not validated. Because this study performed matching from the sagittal plane of the cineradiograph, studies using biplane cineradiography with greater detail are necessary in the future. Further investigations will help more clearly elucidate these topics.

\section{Conclusions}

The results of this study showed differences in the eversion and external rotation of the subtalar joint, navicular height change, and calcaneal pitch between normal participants and patients with MTSS. The subtalar of patients with MTSS is particularly associated with increased external rotation and eversion.

\section{Abbreviations}

MTSS: Medial tibial stress syndrome.

\section{Competing interests}

The authors state that they have no financial competing interest and source of funding.

\section{Authors' contributions}

KA, TF conceived and designed the study, KA, BN, MF, SM, TF performed the experiments, $\mathrm{KA}, \mathrm{MF}, \mathrm{NH}$ performed data analysis and drafted the manuscript. $\mathrm{MF}, \mathrm{NH}$ contributed to discussion and reviewed/edited the manuscript. All authors edited and approved the manuscript prior to the submission.

\section{Acknowledgements}

We would like to thank the staff of Tsukuba University for image acquisition, Editage for English language editing, and Adidas Japan for providing instrument.

\section{Author details}

${ }^{1}$ Graduate School of Sport Sciences, Waseda University, 2-579-15 Mikajima, Tokorozawa, Saitama 359-1192, Japan. ${ }^{2} J a p a n$ Institute of Sports Sciences, Sports Science, 3-15-1, Nishigaoka, Kita-ku 115-0056, Japan. ${ }^{3}$ Department of Sports Medicine, Graduate School of Comprehensive Human Sciences, University of Tsukuba, 1-1-1 Tennodai, Tsukuba, Ibaraki 305-8577, Japan. ${ }^{4}$ Faculty of Sport Sciences, Waseda University, 2-579-15 Mikajima,

Tokorozawa, Saitama 359-1192, Japan.

Received: 4 March 2015 Accepted: 22 June 2015

Published online: 01 July 2015

\section{References}

1. Mubarak SJ, Gould RN, Lee YF, Schmidt DA, Hargens AR. The medial tibial stress syndrome. A cause of shin splints. Am J Sports Med. 1982;10:201-5.

2. Clanton TO, Solcher BW. Chronic leg pain in the athlete. Clin Sports Med. 1994;13:743-59.

3. Moen MH, Tol JL, Weir A, Steunebrink M, De Winter TC. Medial tibial stress syndrome: a critical review. Sports Med. 2009;39:523-46.

4. Clement DB. Tibial stress syndrome in athletes. J Sports Med. 1974;2:81-5.

5. Beck BR, Osternig LR. Medial tibial stress syndrome: the location of muscles in the leg in relation to symptoms. J Bone Joint Surg Am. 1994;76:1057-61.

6. Yates $B$, White $S$. The incidence and risk factors in the development of medial tibial stress syndrome among naval recruits. Am J Sports Med. 2004;32:772-80.

7. Anderson MW, Ugalde V, Batt M, Gacayan J. Shin splints: MR appearance in a preliminary study. Radiology. 1997;204:177-80.

8. Batt ME, Ugalde V, Anderson MW, Shelton DK. A prospective controlled study of diagnostic imaging for acute shin splints. Med Sci Sports Exerc. 1998:30:1564-71.

9. Moen MH, Holtslag L, Bakker E, Barten C, Weir A, Tol JL, et al. The treatment of medial tibial stress syndrome in athletes; a randomized clinical trial. Sports Med Arthrosc Rehabil Ther Technol. 2012;4:12.

10. Bennett JE, Reinking MF, Pluemer B, Pentel A, Seaton M, Killian C. Factors contributing to the development of medial tibial stress syndrome in high school runners. J Orthop Sports Phys Ther. 2001;31:504-10.

11. Newman $P$, Adams R, Waddington $G$. Two simple clinical tests for predicting onset of medial tibial stress syndrome: shin palpation test and shin oedema test. Br J Sports Med. 2012;46:861-4.

12. Sommer HM, Vallentyne SW. Effect of foot posture on the incidence of medial tibial stress syndrome. Med Sci Sports Exerc. 1995;27:800-4.

13. Craig DI. Medial tibial stress syndrome: evidence-based prevention. J Athl Train. 2008:43:316-8.

14. Yagi S, Muneta T, Sekiya I. Incidence and risk factors for medial tibial stress syndrome and tibial stress fracture in high school runners. Knee Surg Sports Traumatol Arthrosc. 2013;21:556-63.

15. Pohl MB, Mullineaux DR, Milner CE, Hamill J, Davis IS. Biomechanical predictors of retrospective tibial stress fractures in runners. J Biomech. 2008;41:1160-5.

16. Viitasalo JT, Kvist M. Some biomechanical aspects of the foot and ankle in athletes with and without shin splints. Am J Sports Med. 1983;11:125-30.

17. Milner CE, Davis IS, Hamill J. Free moment as a predictor of tibial stress fracture in distance runners. J Biomech. 2006;39:2819-25. 
18. Milner CE, Ferber R, Pollard CD, Hamill J, Davis IS. Biomechanical factors associated with tibial stress fracture in female runners. Med Sci Sports Exerc. 2006;38:323-8

19. Milner CE, Hamill J, Davis I. Are knee mechanics during early stance related to tibial stress fracture in runners? Clin Biomech. 2007;22:697-703.

20. Burne SG, Khan KM, Boudville PB, Mallet RJ, Newman PM, Steinman LJ, et al. Risk factors associated with exertional medial tibial pain: a 12 month prospective clinical study. Br J Sports Med. 2004;38:441-5.

21. Reinschmidt C, van den Bogert AJ, Nigg BM, Lundberg A. Murphy N. Effect of skin movement on the analysis of skeletal knee joint motion during running. J Biomech. 1997;30:729-32.

22. Arndt A, Westblad P, Winson I, Hashimoto T, Lundberg A. Ankle and subtalar kinematics measured with intracortical pins during the stance phase of walking. Foot Ankle Int. 2004;25:357-64

23. Reinking MF. Exercise-related leg pain in female collegiate athletes: the influence of intrinsic and extrinsic factors. Am J Sports Med. 2006;34:1500-7.

24. Stacoff A, Reinschmidt C, Nigg BM, van den Bogert AJ, Lundberg A, Denoth J, et al. Effects of foot orthoses on skeletal motion during running. Clin Biomech (Bristol, Avon). 2000;15:54-64.

25. Komistek RD, Stiehl JB, Buechel FF, Northcut EJ, Hajner ME. A determination of ankle kinematics using fluoroscopy. Foot Ankle Int. 2000;21:343-50.

26. Korpelainen R, Orava S, Karpakka J, Siira P, Hulkko A. Risk factors for recurrent stress fractures in athletes. Am J Sports Med. 2001;29:304-10

27. Yamaguchi S, Sasho T, Kato H, Kuroyanagi Y, Banks SA. Ankle and subtalar kinematics during dorsiflexion-plantarflexion activities. Foot Ankle Int. 2009:30:361-6.

28. Grood ES, Suntay WJ. A joint coordinate system for the clinical description of three-dimensional motions: application to the knee. J Biomech Eng. 1983;105:136-44

29. Banks SA, Hodge WA. 2003 Hap Paul award paper of the international society for technology in arthroplasty. Design and activity dependence of kinematics in fixed and mobile-bearing knee arthroplasties. J Arthroplasty. 2004;19:809-16.

30. Prichasuk S, Sinphurmsukskul O. Kidner procedure for symptomatic accessory navicular and its relation to pes planus. Foot Ankle Int. 1995:16:500-3.

31. Wearing SC, Urry S, Perlman PR, Dubois P, Smeathers JE. Serial measurement of calcaneal pitch during midstance. J Am Podiatr Med Assoc. 1999:89:188-93.

32. Campbell KJ, Wilson KJ, LaPrade RF, Clanton TO. Normative rearfoot motion during barefoot and shod walking using biplane fluoroscopy. Knee Surg Sports Traumatol Arthrosc. 2014 Jun 6. [Epub ahead of print].

33. Noh B, Masunari A, Akiyama K, Fukano M, Fukubayashi T, Miyakawa S. Structural deformation of longitudinal arches during running in soccer players with medial tibial stress syndrome. Eur J Sport Sci. 2015;15:173-81.

34. Picciano AM, Rowlands MS, Worrell T. Reliability of open and closed kinetic chain subtalar joint neutral positions and navicular drop test. J Orthop Sports Phys Ther. 1993;18:553-8.

35. Brody DM. Techniques in the evaluation and treatment of the injured runner. Orthop Clin North Am. 1982;13:541-58.

36. Raissi GR, Cherati AD, Mansoori KD, Razi MD. The relationship between lower extremity alignment and Medial Tibial Stress Syndrome among non-professional athletes. Sports Med Arthrosc Rehabil Ther Technol. 2009;1:11. doi:10.1186/1758-2555-1-11.

37. Hubbard TJ, Carpenter EM, Cordova ML. Contributing factors to medial tibia stress syndrome: a prospective investigation. Med Sci Sports Exerc. 2009:41:490-6.

38. Prichasuk S, Subhadrabandhu T. The relationship of pes planus and calcaneal spur to plantar heel pain. Clin Orthop Relat Res. 1994;306:192-6.

39. Tong JW, Kong PW. Association between foot type and lower extremity injuries: Systematic literature review with meta-analysis. J Orthop Sports Phys Ther. 2013:43:700-14.

\section{Submit your next manuscript to BioMed Central and take full advantage of:}

- Convenient online submission

- Thorough peer review

- No space constraints or color figure charges

- Immediate publication on acceptance

- Inclusion in PubMed, CAS, Scopus and Google Scholar

- Research which is freely available for redistribution

Submit your manuscript at www.biomedcentral.com/submit 